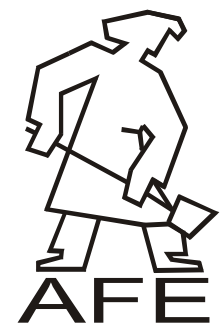

\title{
Kinetics of Hardening and Drying of Ceramic Moulds with the New Generation Binder - Colloidal Silica
}

\author{
J. Zych*, J. Kolczyk \\ AGH University of Science and Technology, Faculty of Foundry Engineering, Reymonta 23, \\ 30-059 Cracow, Poland*Corresponding author. \\ *Corresponding author. E-mail address: jzych@agh.edu.pl
}

Received 26.06.2013; accepted in revised form 02.09.2013

\begin{abstract}
The influence of selected factors on drying ceramic moulds applied in the investment casting technology was determined by the gravimetric method. Moulds produced of ceramic sands based on the new generation binders - colloidal silica, were investigated. It was found that each successive layer, of a similar thickness, is drying longer than the previous one. The drying time of layers forming closed spaces is several times longer as compared with drying open surfaces (external). Grain size of matrix used for moulds sprinkling has none significant influence on drying rates.
\end{abstract}

Keywords: Innovative Foundry Technologies and Materials, Colloidal binder, Investment castings, Drying rate, Technological factors.

\section{Introduction}

Multi-layer ceramic moulds are built of liquid ceramic sand and a refractory material forming their matrices. Liquid sands are prepared from aqueous binding agent and colloidal silica (in a new technology) or ethyl silicate (in an older technology) and a fire-resisting, fine-grained matrix. As a powder topping of external mould layers a coarse-grained matrix, being also a refractory material, is used.

Performing a multi-layer mould comprises several stages, among others:

- making wax patterns and joining them in sets,

- preparation of ceramic sand and depositing of successive layers, powdering them with a matrix of various grain size,

- wax removal from a mould (melting in autoclave),

- moulds drying at temperatures: $50-120^{\circ} \mathrm{C}$,
- $\quad$ annealing of moulds at temperatures: from $400-1100^{\circ} \mathrm{C}$,

- moulds pouring with liquid metal,

- $\quad$ casting knocking out and purification [3, 6].

From the moment when the European Union introduced regulations concerning the environment protection requiring substitution of alcoholic binders by aqueous binders, several difficulties in making moulds occurred. Substituting binding materials with additions of ethyl silicate by the new generation aqueous binders causes various problems. One of them concerns drying of mould layers deposited on a wax pattern. Ethyl alcohol has a higher vapour pressure than water. It is more volatile since has a lower boiling point (it means evaporates faster) [2] and therefore the drying process is shorter. An application of aqueous binding materials prolongs mould drying times.

Drying is a technological procedure during which water is removed from semi-finished products to a level which is proper for their further application in the technological process. 
A compact moisture content in material constitutes water which is present both on grain surfaces and inside them. The drying process is a two-stage one. The first - leads to water evaporation from surfaces, and the second - being a moisture diffusion from inside of the product to its surface layer [1].

The first layer decides on the ceramic mould properties. Each next layer strengthens the mould providing its higher strength. This strength should be high enough to prevent the mould destruction during its pouring, and simultaneously enough elastic to prevent too high stresses during crystallising, since they could cause a mould cracking.

A very important element of the process is a determination of drying times of successively deposited layers. When a coating is not dry enough, at each successive deposition of a sand layer cracks are formed, which causes a strength decrease and a ceramic mould damage.

Data concerning the kinetics of hardening ceramic layers with an application of the new ultrasound measuring method are available in the literature [8-10]. These investigations allow to monitor the kinetics of elasticity and strength changes of moulds. There are also works in which investigations concerning drying of layers under conditions of a forced air circulation for openings and cavities of various lengths - are described [4]. To improve the quality, strength and drying acceleration the silica sols of 3-4 times larger $\mathrm{SiO}_{2}$ particles and their $40 \%$ concentration in a colloid were applied $[5,7]$.

\section{Description of the measuring equipment}

Investigations of the drying procedure of successively deposited layers of a ceramic mould were performed by the gravimetric method by means of the electronic weighter RADWAG.

A
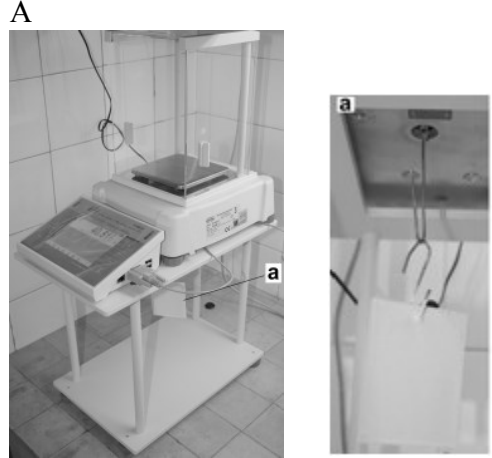

B

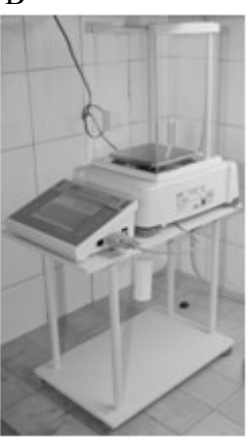

Fig. 1. Suspension by means of a weighter: A- Wax pattern

of a plate, B- Wax pattern of a bushing with a through opening

In drying tests of a ceramic mould an influence of a matrix grain size (for powder topping) on the drying process of three successive layers made of ceramic sand on the basis of colloidal silica Ludox AM was investigated.

Wax patterns with the deposited layer and powder topping were suspended on the electronic weighter what provided the possibility of on line monitoring the drying process. Such way of samples mounting (Fig. 1) allowed for a uniform drying of the deposited layers from each side. Tests of drying procedures were performed under approximately constant conditions, at the air moisture content within the range $\mathrm{W}=45-50 \%$ and ambient temperature $\mathrm{T}_{\mathrm{ot} .}=22-24^{\circ} \mathrm{C}$.

\section{Preparation of samples}

Investigations of drying of successive layers of a ceramic mould were performed for two shapes of wax patterns. The comparison of drying of 'open' and 'closed' layers was the aim of these tests. In order to obtain wax patterns, at first two different matrices were made, which after pouring with wax gave pattern shapes seen in Figure 2a and b. a

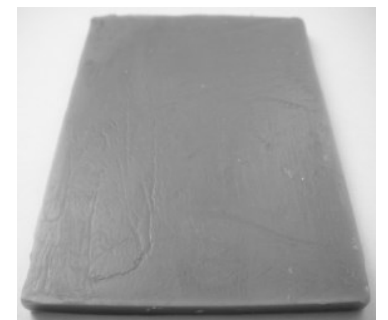

b

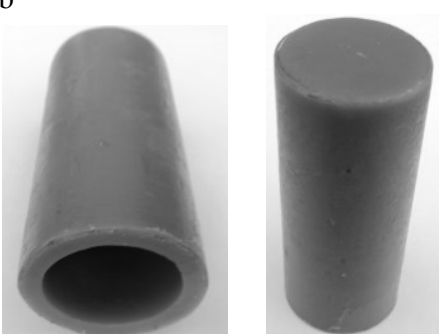

Fig. 2. Wax patterns for depositing layers of a shape of: a) Plate b) Bushing with a bottom

Three successive layers of a ceramic sand were deposited on the prepared and degreased wax patterns and then sprinkled with a matrix. Detailed data concerning the successive layers are presented in Table 1.

One of the most important parameters influencing the quality of the produced moulds, and in consequence the casting quality, is the ceramic liquid mixture composition.

Binding materials and ceramic sands prepared with them should be characterised by: proper refractoriness, lack of reactivity with a metallic material, small thermal expansion, stability of properties, easiness of purification, permeability and strength during mould pouring with liquid metal. 
Table 1.

Wax pattern sizes and technologies of making multi-layer ceramic moulds

\begin{tabular}{|c|c|c|}
\hline & \multicolumn{2}{|c|}{ Type of wax pattern } \\
\hline & Plate & $\begin{array}{c}\text { Bushing with } \\
\text { a battom }\end{array}$ \\
\hline $\begin{array}{c}\text { Dimensions } \\
\text { [mm] }\end{array}$ & $90 \times 70 \times 5$ & $\begin{array}{l}1=84,0 \\
D=35,5 \\
d=25,5\end{array}$ \\
\hline $\begin{array}{l}\text { Type of } \\
\text { matrix }\end{array}$ & $\begin{array}{l}\text { a)CMC + Mullit I } \\
\text { (three layers), } \\
\text { b)CMC + Mullit II } \\
\text { (three layers), } \\
\text { c)CMC + Mullit III } \\
\text { (three layers), } \\
\text { d)CMC + Mullit I- first } \\
\text { layer, Mullit II - } \\
\text { second layer, Mullit III- } \\
\text { third layer. }\end{array}$ & $\begin{array}{l}\text { a) CMC + Mullit I } \\
\text { (second layer)- } \\
\text { external surface, } \\
\text { b) CMC + Mullit I } \\
\text { (second layer)- } \\
\text { internal surface. }\end{array}$ \\
\hline $\begin{array}{l}\text { l - length, } \\
\text { D - nominal } \\
\text { d - internal }\end{array}$ & $\begin{array}{l}\text { eter, } \\
\text { ter. }\end{array}$ & \\
\hline
\end{tabular}

Grain size of matrix used as materials for sprinkling in tests are listed in Table 2

Table 2.

Grain size of matrix (material for sprinkling) applied at a ceramic moulds production

\section{Kind of the applied matrix}

Mullit I

108,51
326,46

624,99
Mullit III

$\mathbf{d}_{\mathbf{a}}-$ arithmetical average

\section{Drying of flat external layers (plate - wax pattern)}

Diagrams presenting drying time of successive mould layers, which were sprinkled with matrices of various grain sizes (Table 2) are presented as examples in Figures 3 to 6.

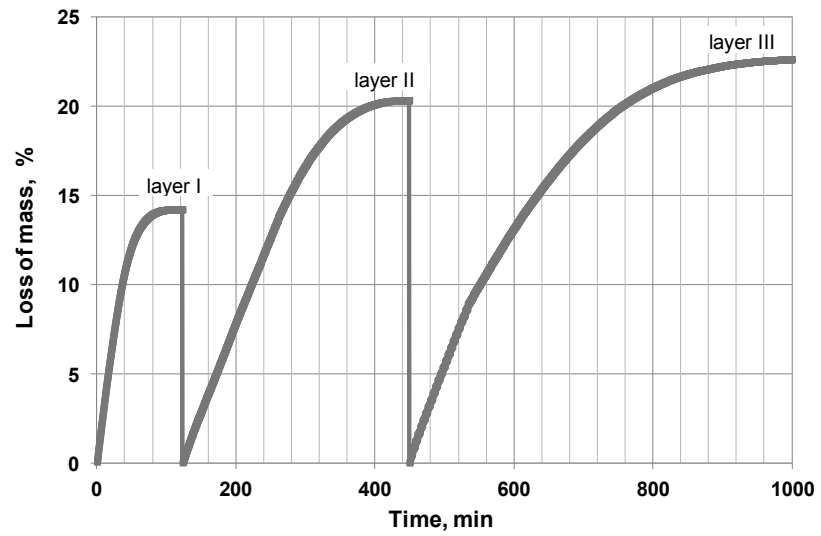

Fig. 3. Drying characteristic of three layers of the ceramic sand with the Ludox AM binder, matrix - Mullit I

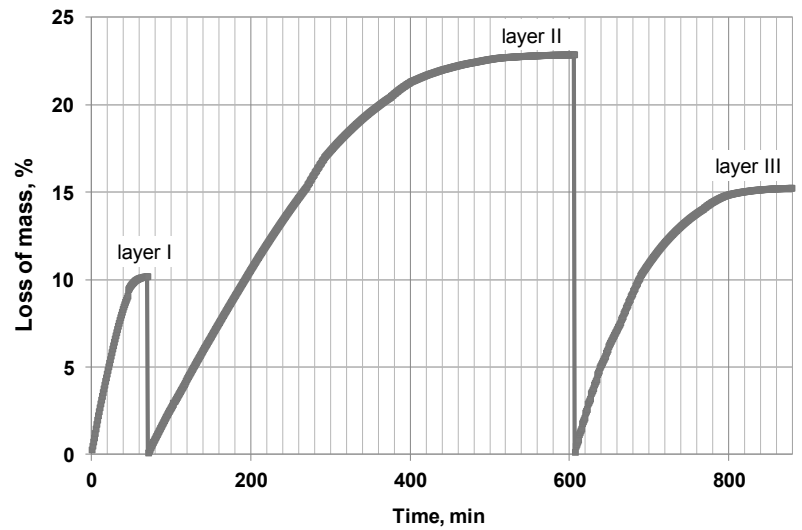

Fig. 4. Drying characteristic of three layers of the ceramic sand with the Ludox AM binder, matrix - Mullit II

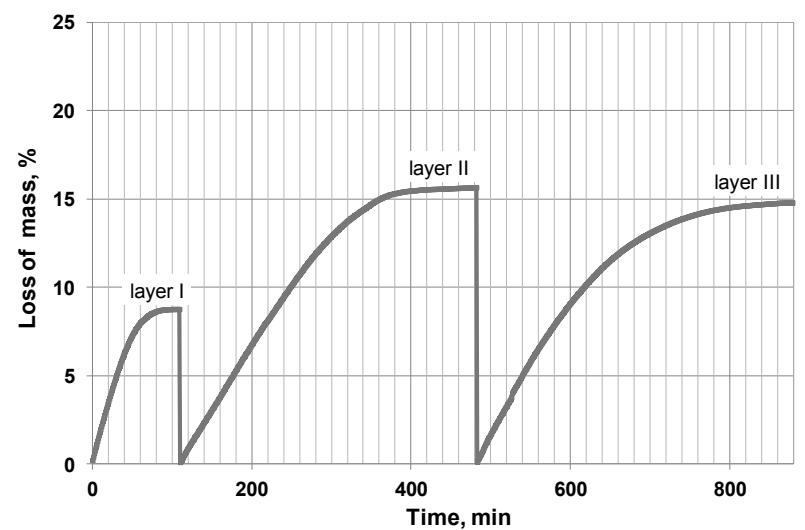

Fig. 5. Drying characteristic of three layers of the ceramic sand with the Ludox AM binder, matrix - Mullit III 


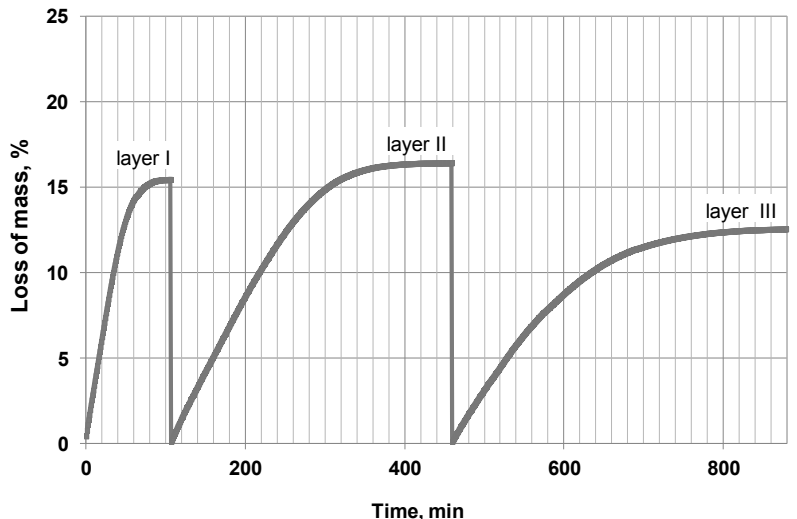

Fig. 6. Drying characteristic of three layers of the ceramic sand with the Ludox AM binder and successive matrices:

1-st layer matrix: - Mullit I, 2-nd layer matrix: - Mullit II, 3-rd layer matrix: - Mullit III

The obtained results concerning the applied matrix influence on the drying time of individual layers are listed in Figure 7.

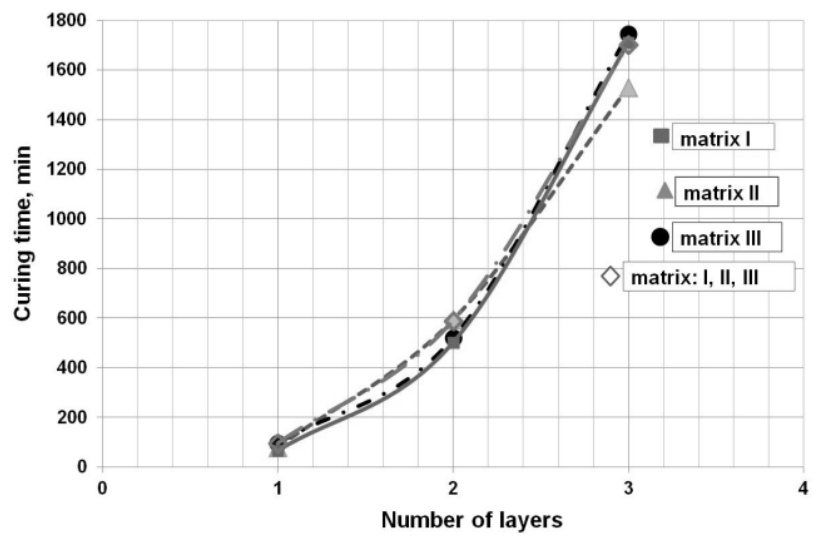

Fig. 7. Matrix grain size influence on the drying time of individual layers of the ceramic mould

The results of tests concerning the drying time of individual layers of the ceramic mould, made on the basis of the colloidal aqueous binder, where the wax plate was used as a pattern, are presented. Sizes of this wax plate are given in Table 1. Samples were dried in an ambient temperature .

The drying time of individual layers can be determined from the presented characteristic. Ceramic moulds are not uniformly built. Depositing of individual layers of a ceramic sand leads to increasing a mould thickness and prolongation of a drying time (Fig.3 to 6).

It results, from the performed tests, that the grain size of the applied matrix practically does not influence the mould drying time, while deposition of each successive coating causes prolongation of the drying time of the multi-layer ceramic mould.

\section{Drying of external and internal surfaces (bushing - wax pattern)}

Investigations of the layers drying process with the application of the bushing as the wax pattern were performed in the same way as when the flat plate was used. As a matrix for sprinkling internal and external surfaces Mullit I was used.

The aim of these tests was a determination and comparison of drying times of sand layers deposited on external and internal surfaces of the wax pattern.

The diagram presented in Figure 8 presents kinetics of drying of three layers of the ceramic sand with the matrix - Mullit I deposited on external surfaces of the bushing wax pattern.

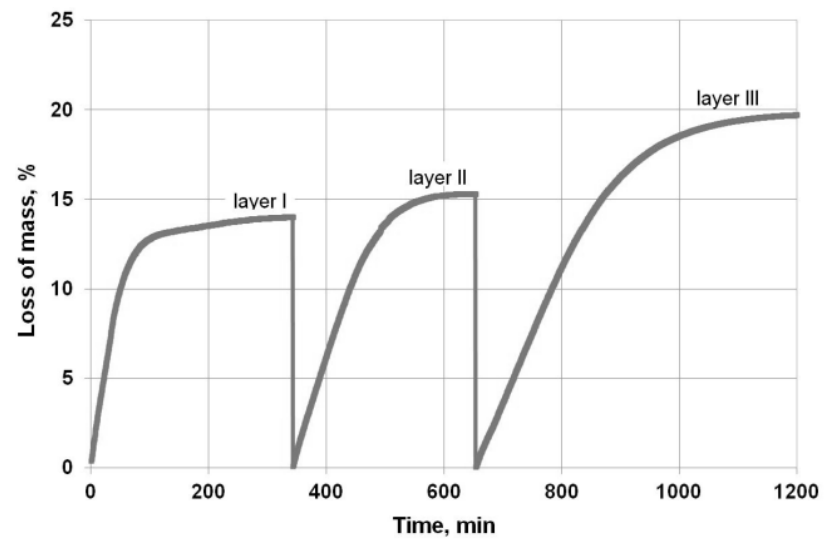

Fig. 8. Drying kinetics of successive (external) layers of the ceramic sand made with the Ludox AM binder with the Mullit I matrix. Wax pattern: bushing with a bottom

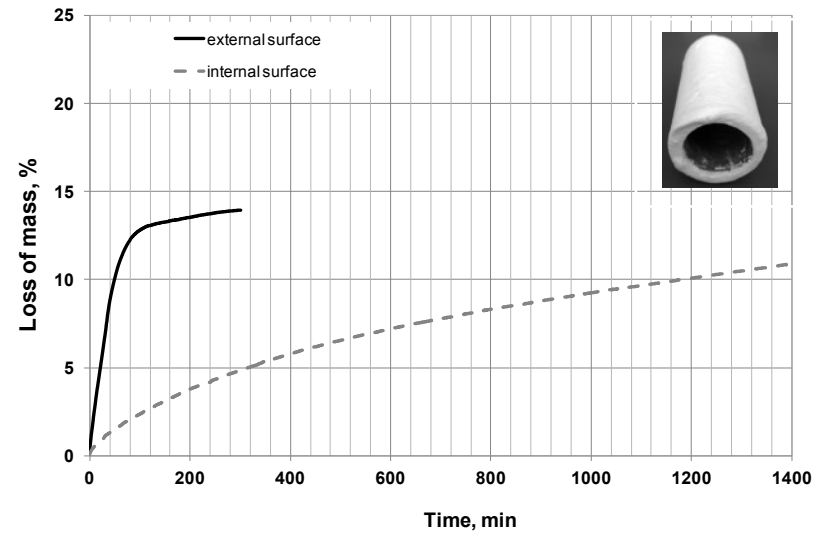

Fig. 9. Drying kinetics of the first layer of the ceramic sand (with the Mullit I matrix) of external and internal surfaces of the pattern in a bushing shape 


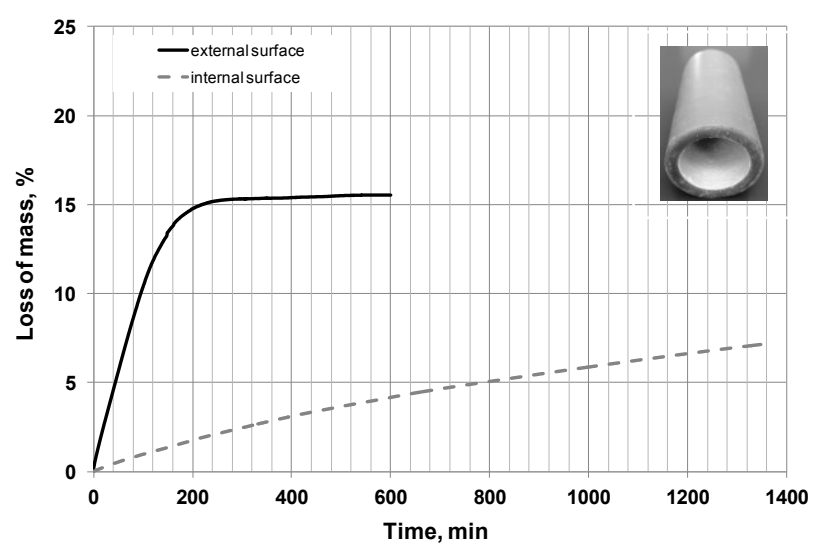

Fig. 10. Drying kinetics of the second layer of the ceramic sand (with the Mullit I matrix) external and internal surfaces of the pattern in a bushing shape

The performed investigations confirm practical observations concerning a longer drying time of the layer deposited on the internal surface of the wax pattern, both for the first and the second layer.

In case of external surfaces the clear finish of the drying process is seen and the time after which the coating will be completely dried, can be exactly determined. In case of internal surfaces both the first and the second coating is drying several times longer. The first layer dries nearly 5-times longer and the second one 4-times longer than coatings deposited on external surfaces.

External surfaces are in contact with surroundings and dry faster and uniformly. In case of internal surfaces, due to not having direct contacts with surroundings, the mass decrease in samples is slower.

An air moisture content inside a sample increases due to water evaporation from the ceramic sand into the mould. An increase of a moisture content above the evaporation surface hampers a further water evaporation process. Such conditions cause prolongations of the drying process. This process is significantly slower which - in turn - unfavourably influences production of a multi-layer ceramic mould.

\section{Conclusions}

The obtained results allow to draw several important conclusions on the kinetics of drying of moulds made of ceramic sands with a colloidal binder - colloidal silica - the new generation binder.

- Regardless of the fact that successive layers are of approximately the same thickness their drying time is not the same. Each successive coating dries longer than the previous one. This effect is observed for external surfaces both flat and cylindrical.
- $\quad$ Grain size of a matrix used for sprinkling moulds does not have any essential influence on the drying of successive layers.

- $\quad$ Large differences in the drying rates occur between external and internal surfaces. Internal surfaces, especially directed towards bottom, are drying much slower. Without a forced air circulation a proper mould drying in such spaces is very long-lasting.

\section{Acknowledgements}

The study was performed as the "Dean Project 2013", No. 15.11.170.420.

\section{References}

[1] Dańko, J., Holtzer, M., Małolepszy, J., Pytel, Z., Dańko, R., Gawlicki, M., Łagosz, A. (2010). Methods of limitation of waste from foundry processes and methods of their management (s. 23-165). Kraków: AKAPIT (in Polish).

[2] Barrow, G.M. (1973). Physical chemistry. Warszawa: PWN (in Polish).

[3] Karwiński, A., Wieliczko, P. \& Leśniewski, W. (2006). Application of surface active agents in the investment casting process. Inżynieria Aparatura Chemiczna, nt.5 s, 58-60 (in Polish).

[4] Karwiński, A. (1999). Ecosil - water-based binder for investment casting. Biuletyn Instytutu Odlewnictwa 5, s. 315.

[5] Karwiński, A. (1997). The influence of the colloid silica content on the properties of liquid ceramic slurry used in investment casting. Krzepniecie Metali i Stopów, No. 31, 89-96 (in Polish).

[6] Lechowa, L., Stachańczyk, J., Łepniak. (1980). Investment casting. Instytut Odlewnictwa,nr 3, 680-683 (in Polish).

[7] Piłkowski, Z., Nadolski, M. (2004). Some strenght problems of sheell molds for investmens casting. Archives of Foundry, 4(14), 413-419 (in Polish).

[8] Zych, J. Method of examining the hardening process of core and moulding sand mixes containing a hardenable binder. Akademia Górniczo-Hutnicza : G01N 29/00 (2006.01) Polska- opis patentowy; PL 192202 B1.

[9] Zych, J.(2006). Moulding sands surface layer-kinetics of the changes its property. Archiwum Odlewnictwa. 6 (20), 77-84.

[10] Zych, J. (2006). Application of the novel ultrasonic method in the on line research of the setting, and hardening process of ceramic materials. Inżynieria Materiałowa. XXVII, vol. 151 (in Polish). 